\title{
Food safety knowledge and practice among elderly people living at home
}

Angela E Johnson, Angela J M Donkin, Kevin Morgan, Jeanette M Lilley, Roger J Neale, Robert M Page, Richard Silburn
Department of Health Care of the Elderly, The University of Nottingham, Queens Medical Centre, Nottingham A E Johnson A J M Donkin J M Lilley

Centre for Ageing and Rehabilitation Studies, University of Sheffield, School of Health and Related Research, Community Sciences Centre, Northern General Hospital, Sheffield S5 7AU K Morgan

Department of Applied Biochemistry and Food Science, The University of Nottingham, Sutton Bonnington, Leicestershire R J Neale

School of Social Studies, The University of Nottingham, University Park, Nottingham R M Page R Silburn

Correspondence to: Dr Morgan.

Accepted for publication 25 February 1998

\begin{abstract}
Objective-To assess the food storage knowledge and practice of elderly people living at home.

Methods-Three phase survey data collection: face to face interviews; dietary diaries with a food frequency questionnaire; and follow up interviews.

Setting-Urban Nottingham.

Participants-809 elderly people (aged 65+) randomly selected from general practitioner lists.

Main outcome measures-Respondent's refrigerator temperature; knowledge of freezer star rating; understanding of "use by" and "sell by" dates; reported ability to read food product safety labels.

Results-From a weighted total of 645 refrigerators measured, $451(70 \%)$ were too warm for the safe storage of food ( $\geqslant 6^{\circ}$ Celsius). Only $41 \%$ of respondents ( $n=279)$ knew the star rating of their freezer. Within a smaller sub-sample knowledge of the "use by" and "sell by" dates was good, but $45 \%$ of these respondents reported difficulty reading food labels. The storage of foods at inappropriate temperatures was not independent of socioeconomic or demographic status, and tended to be more likely among the poorer and those not living alone.

Conclusions-Food storage practices among the majority of elderly people interviewed in this study do not meet recommended safety standards to minimise the risk of food poisoning.

(F Epidemiol Community Health 1998;52:745-748)
\end{abstract}

While reports of food poisoning in the United Kingdom tend to be lowest for those aged 65 years and over, ${ }^{12}$ this age group has the poorest prognosis when food poisoning occurs. ${ }^{3-5}$ Several studies have identified food prepared in the family home as a major source of such poisoning, with foodborne diseases closely related to both the temperature and duration of food storage..$^{6-11}$ Previous research, however, indicates that consumers generally: lack awareness of the dangers of storing food at the wrong temperature ${ }^{26}$; lack knowledge about correct refrigerator temperatures ${ }^{261213}$; tend not to associate storage duration with the risk of foodborne disease ${ }^{26}$; and often pay little attention to "use by" dates. ${ }^{12} 13$ As retired and elderly people eat a high proportion of their meals at home, ${ }^{67}$ and as most research on consumer food safety has focused on younger people, the food storage practices of older people merit particular attention. Using data from a wide ranging study of food purchasing and consumption in later life, the following analyses were designed to explore the food safety practices and knowledge of elderly people with particular reference to the storage temperature of perishable food, and knowledge of factors influencing storage duration.

\section{Methods}

SAMPLE

From a total of 159 general practitioners with patients residing within the Nottingham City boundary $127(78 \%)$ agreed to support the study. With the consent and cooperation of these general practitioners Nottinghamshire Family Health Services Authority age-sex lists were used to identify all non-institutionalised people aged 65 years and over living within the Nottingham area. From the resulting sampling frame of 26055 people, sufficient people were randomly selected to provide the target of 800 completed interviews. The resulting sample of 1584 was stratified at age 75 with equal probability representation in the age groups 65-74 and 75+. Respondents were invited by letter to participate before being approached by the survey interviewer.

\section{DATA COLLECTION}

The study comprised three phases of data collection as follows.

\section{Phase 1}

Face to face interviews were conducted within the whole target sample using a structured questionnaire covering aspects of diet, health, shopping behaviour, household composition, and socioeconomic status. Respondents were specifically asked about ownership of a refrigerator and freezer, and knowledge of the star rating of the freezer. Refrigerator temperatures were measured using a spirit filled fridge/ freezer thermometer supplied by the Environmental Health Department of Gedling Borough Council (Electronic Temperature Instruments Limited) which read from -30 to $+40^{\circ}$ Celsius. Refrigerator temperatures were measured in accordance with guidelines provided by the Food Safety Directorate. ${ }^{15}$ Thus, thermometers were placed on the top shelf of refrigerators with a freezer compartment, but on the bottom shelf of larder-type refrigerators. Thermometers were placed in the refrigerator at the start of the interview, and retrieved after the interview (mean time 54 minutes, SD 12 minutes). All interviews were conducted from a lap-top computer in the respondent's own home. 
Table 1 Patients characteristics (weighted) of Phase 1 sample

\begin{tabular}{lllr}
\hline & & Number & $\%$ \\
\hline Age & 65-74 (unweighted) & 392 & 48.5 \\
& $75+$ (unweighted) & 417 & 51.5 \\
& $65-74$ & 392 & 57.0 \\
Sex & $75+$ & 296 & 43.0 \\
Social class & Female & 388 & 56.5 \\
& Male & 299 & 43.5 \\
\multirow{2}{*}{ Qualifications } & Professional/managerial (I and II) & 100 & 14.5 \\
& Skilled (manual and non-manual) (IIM and IIN) & 415 & 60.4 \\
& Semi- and unskilled (IV and V) & 173 & 25.1 \\
Lives alone & No qualifications & 555 & 80.8 \\
& Qualifications on leaving school & 31 & 4.5 \\
& Further qualifications after leaving school & 101 & 14.7 \\
& Yes & 262 & 38.1 \\
& No & 426 & 62.0 \\
\hline
\end{tabular}

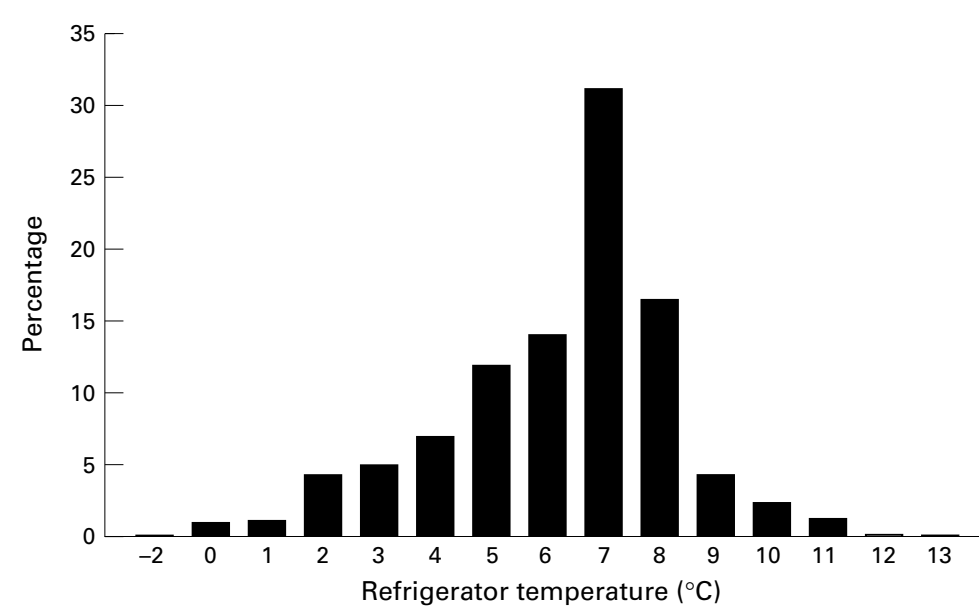

Figure 1 Weighted distribution of 645 refrigerator temperatures recorded in the homes of people aged $65+\left(\right.$ recommended safe temperature $\left.=0-5^{\circ} C^{15}\right)$.

Phase 2

On completion of the Phase 1 interview a $50 \%$ sub-sample of respondents was randomly selected to complete self administered four day dietary diaries and food frequency questionnaires.

Phase 3

A further $50 \%$ sub-sample of Phase 2 respondents was then selected to participate in a detailed follow up interview covering aspects of nutritional and food safety knowledge, and influences on food choices and preferences. All Phase 3 respondents were shown the enlarged text of typical food label information and asked to define the "use by" and "sell by" dates. Questions were also asked about the respondent's ability to read normal sized food labels. Finally, respondents were asked to identify their greatest food related health concern from the following list: getting heart disease or cancer from eating the wrong foods; getting food poisoning; the effects of chemical residues like pesticides; obesity; the effects of artificial colourings and flavourings; and contracting animal diseases such as BSE. A "none of these" category was also provided. Data collection was conducted over a 16 month period from January 1995 to May 1996.

The present analyses use data from phases 1 and 3 only.

ANALYSIS

To compensate for the intentional over sampling of the age group $75+$, weights were calcu-
KEY POINTS

- Elderly people are the largest group at risk of mortality from food poisoning.

- Food storage practices among older people have been under-researched.

- This study found that $70 \%$ of older respondent's refrigerators were too warm for the safe storage of food.

- While "use by" and "sell by" dates were well understood, $45 \%$ of respondents had difficulty reading these food labels.

- Standards of food hygiene among elderly people could be greatly improved through attention to storage and labelling practices.

lated based on the expected ratio of those aged 65-74 to those aged $75+$ as indicated by the 1991 census. To provide population estimates from the stratified sample, the present analyses use weighted data throughout. Economic status was estimated from income data provided at the Phase 1 interview. Taking into account whether respondents were living alone or as a couple, those with weekly incomes below $50 \%$ of the average household income (based on national estimates current at the time of the survey ${ }^{14}$ ) were judged to be economically vulnerable. Educational qualifications were divided into three groups: no qualifications; qualifications on leaving school only; further qualifications. The "correct" refrigerator temperature for storing food was considered to be 0 to $5^{\circ} \mathrm{C}$. ${ }^{15}$ To identify the independent contribution of social and economic factors to food safety issues, selected demographic variables were entered into two separate logistic regression models with refrigerator temperature (correct/incorrect) and knowing freezer star rating (yes/no) as dependent. In both models independent variables were: sex; chronological age; economic vulnerability (yes/no); educational qualifications; and living alone (yes/no). Variables selection was by the forward stepwise method. Model parameters are expressed as odds ratios (OR) with $95 \%$ confidence intervals. All analyses were performed using SPSS for Windows version 6.0. ${ }^{16}$

\section{Results}

From a total of 1281 respondents approached to take part in the study, 848 (66\%) agreed to participate. Excluding those with significant cognitive impairment, and incomplete interviews, 809 respondents (63\%) completed the Phase 1 interview, 361 (45\%) of these completed the Phase 2 diary, and 177 (49\%) of these completed the Phase 3 follow up interview (weighted numbers $=688,313$, and 154 respectively). Table 1 shows the patients' characteristics of the Phase 1 sample.

\section{Phase 1 data}

Most of the respondents (weighted prevalence $=99 \%$ ) had a refrigerator. From a weighted total of 645 refrigerators measured, 451 (70\%) were found to be too warm, with temperatures 
Table 2 Food concerns selected by 154 elderly respondents (weighted data)

\begin{tabular}{ll}
\hline Food safety issue & $\begin{array}{l}\text { Rated as } \\
\text { greatest concern: } \\
\text { number } \\
\text { (\%) }\end{array}$ \\
\hline Getting food poisoning & $37(24.3)$ \\
Getting heart disease or cancer from eating the wrong foods & $21(13.8)$ \\
The effects of chemical residues (for example, pesticides) & $18(11.8)$ \\
Obesity & $15(9.9)$ \\
The effects of artificial additives such as colourings and flavourings & $10(6.6)$ \\
Animal diseases (for example, BSE) spreading to people & $6(4.0)$ \\
Not concerned about any of these & $45(29.6)$ \\
\hline
\end{tabular}

ranging from 6 to $13^{\circ} \mathrm{C}$ (fig 1). Only one refrigerator was found to be too cold at $-2^{\circ} \mathrm{C}$. In the logistic regression analysis not living alone $(\mathrm{OR}=1.55,95 \% \mathrm{CI}=1.06,2.26, \mathrm{p}=$ $0.02)$ and lower income $(\mathrm{OR}=1.73,95 \% \mathrm{CI}=$ $1.18,2.54, \mathrm{p}=0.005$ ) were independently associated with having a refrigerator that was too warm.

Most respondents ( $n=673$, weighted prevalence $=98 \%$ ) had the facility to store frozen food, with 545 (weighted prevalence $=81 \%$ ) owning a large capacity freezer (big enough to accommodate "a large joint of meat or a Christmas turkey"), and 125 (weighted prevalence $=19 \%$ ) owning a small capacity freezer/ ice box (room for just a few small packets). Only 279 respondents (weighted prevalence $=$ $41 \%$ ) knew the star rating of their freezer. Logistic regression indicated that female sex $(\mathrm{OR}=2.12,95 \% \mathrm{CI}=1.49,2.99, \mathrm{p}=$ $0.00001)$ and younger age $(\mathrm{OR}=0.95,95 \% \mathrm{CI}$ $=0.92,1.03, \mathrm{p}=0.0002$ per year increase in age) were independently associated with knowing the star rating.

Phase 3 data

The use by date tells the customer when the product should be eaten by, after this date the quality of the product will decrease and for foods such as meat, their microbiological safety becomes questionable. This term was understood by 138 (weighted prevalence $=90 \%$ ) of Phase 3 respondents. The sell by date informs both suppliers and shoppers of the last date when the product should be made available for sale. It is not an indicator of unfit food as such items may still be safe to eat after the sell by date. Fewer respondents (weighted prevalence $=79 \%$ ) knew the correct definition of the sell by date. As regards the readability of labels, 69 Phase 3 respondents (weighted prevalence $=$ $45 \%$ ) reported that they had difficulty reading food labels either because of poor eyesight $(n=$ 48 ), or because the print was too small or too cramped $(n=11)$. Finally, of the six food safety issues offered, getting food poisoning was the most frequently rated as the greatest concern (table 2).

\section{Discussion}

While the refusal rate was relatively high $(34 \%)$, the resulting sample, in terms of age, sex and the number of people living alone, closely matched the host population (as described in the 1991 Census). Many of those contacted ( $20 \%$ of refusals) felt that they were too ill to participate in a study of this kind, while a further $10 \%$ felt the three phase study design too demanding given their present commitments.

The results indicate that a large proportion of elderly people ( $70 \%$ in this study) keep their refrigerator at a temperature too warm to inhibit the growth of micro-organisms, including Escherichia coli. The health impact of storing food at the wrong temperature may be mitigated by the frequency of food shopping, and hence the turnover of food products in the refrigerator. While we have no direct data on the length of food storage it is relevant to note that 557 (weighted prevalence $=81 \%$ ) of Phase 1 respondents said they kept their refrigerator stocked with food. The increased risk of having a refrigerator that was too warm among the economically vulnerable is a particular cause for concern, and may indicate the greater age, and poorer working order, of refrigerators within this sub-group. A similarly increased risk among those not living alone (that is, those living in households of two or more) is less easily explained. One possibility, however, is that after adjustment for age, sex and income, living alone may act as a marker for higher levels of hygiene, caution, and control in the household.

Only $41 \%$ of respondents knew the star rating of their freezer suggesting that, for the majority, frozen foods are purchased without a clear appreciation of safe storage duration. The risk of not possessing such information was significantly increased among the older, and among men. While the former result possibly indicates a cohort effect in the awareness of technical specifications, the latter is consistent with sex divisions in domestic roles within this age group. Respondents knowledge of the "use by" and, to a lesser extent, the "sell by" date, was good. It is clear, however, that for the majority this knowledge may not guide purchasing or storage decisions because $45 \%$ of Phase 3 respondents experienced difficulty reading food labels. Given the two main reasons for poor label readability (print that was too small and cramped, and poor eyesight uncorrected by glasses) it is reasonable to conclude that larger, clearer labels could contribute to food storage safety in this age group. Similarly, an improved understanding of appropriate storage temperatures, and the more widespread use of refrigerator thermometers among vulnerable elderly groups could also reduce the risk of foodborne disease in the home. In the light of recent concern regarding food safety "from the farm to the fork", ${ }^{17}$ these results provide both insights into the food safety knowledge and practices of older people, and a benchmark for future food safety research.

Funding: this research was funded under the Economic and Social Research Council programme The Nation's Diet: the Social Science of Food Choice, and the Ministry of Agriculture, Fisheries and Food open contracting scheme.

Conflicts of interest: none.

The authors thank the participating general practitioners and the field interviewers, Mrs Jennifer Brookes for coordinating the the field interviewers, Mrs Jennifer Brookes for coordinating the
interviews, and to Dr Sally Herne for contributions to the interviews, and to Dr Sally $\mathrm{H}$
Health and Diet questionnaire. 
1 OPCS. Communicable disease statistics 1994. Series MB2 No. 21. London: HMSO, 1996.

2 Food and Drink Federation. National Food Safety Report. London: 1996.

3 Fox RA. The effect of ageing on the immune response. In Fox RA, editor. Immunology and infection in the elderly. 1s ed. Edinburgh: Churchill Livingstone, 1984:289-309.

4 Chandra RK. The relation between immunology, nutrition and disease in elderly people. Age Ageing 1990;19:31.

5 OPCS. Mortality statistics 1993: Cause. Series DH2 No.20. London: HMSO, 1997.

6 Ministry of Agriculture Fisheries and Food. Food hygiene Report on a consumer survey 1988. London: MAFF, 1988.

Ministry of Agriculture Fisheries and Food. National Food Survey 1994. London: HMSO, 1995.

8 Bean NH, Griffin PM. Foodborne disease outbreaks in the United States, 1973-1987: pathogens, vehicles and trends. fournal of Food Protection 1990;53:804-17.

9 Roberts D. Factors contributing to outbreaks of food poisoning in England and Wales 1970-1979. Fournal of poisoning in England
Hygiene 1982;89:491-8.
10 Bryan FL. Factors that contribute to outbreaks of foodborne disease. Fournal of Food Protection 1978;41:81627.

11 Todd ECD. Factors that contributed to foodborne disease in Canada 1973-1977. Fournal of Food Protection 1983;46: $737-47$

12 Spriegel G. Food safety in the home. Nutrition and Food Science 1991;November/December:14-15.

13 Walker A. Food safety in the home. A survey of public awareness. A report on ONS Omnibus Survey data produced on behalf of the Department of Health 1996. London: HMSO, 1996.

14 Department of Social Security. Households below average income: a statistical analysis 1979-1993/4. London: Stationery Office, 1996.

15 Ministry of Agriculture Fisheries and Food. Keeping food cool and safe. London: The Food Safety Directorate, 1994.

16 Norusis MJ. SPSS for Windows: Professional Statistics, Release Norusis MJ. SPSS for Windows:
6.0. Chicago: SPSS Inc, 1993.

17 Christie B. E coli report calls for better food safety. BMF 1997;314:1147. 